\title{
RhoA mediates the expression of acidic extracellular pH-induced matrix metalloproteinase-9 mRNA through phospholipase D1 in mouse metastatic B16-BL6 melanoma cells
}

\author{
TOYONOBU MAEDA $^{1 *}$, SATOSHI YUZAWA ${ }^{1 *}$, ATSUKO SUZUKI ${ }^{1}$, \\ YUH BABA $^{2}$, YUKIO NISHIMURA ${ }^{3}$ and YASUMASA KATO ${ }^{1}$
}

Departments of ${ }^{1}$ Oral Function and Molecular Biology and ${ }^{2}$ General Clinical Medicine, Ohu University School of Dentistry,
Koriyama 963-8611; ${ }^{3}$ Kyushu University Graduate School of Pharmaceutical Sciences, Fukuoka 812-8582, Japan

Received November 2, 2015; Accepted December 10, 2015

DOI: 10.3892/ijo.2016.3322

\begin{abstract}
Solid tumors are characterized by acidic extracellular $\mathrm{pH}\left(\mathrm{pH}_{e}\right)$. The present study examined the contribution of small GTP-binding proteins to phospholipase D (PLD) activation of acidic $\mathrm{pH}_{e}$-induced matrix metalloproteinase-9 (MMP-9) production. Acidic $\mathrm{pH}_{e}$-induced MMP-9 production was reduced by $\mathrm{C} 3$ exoenzyme, which inhibits the Rho family of GTPases; cytochalasin D, which inhibits actin reorganization; and simvastatin, which inhibits geranylgeranylation of Rho. Small interfering RNA (siRNA) against RhoA, but not against $R a c l$ or $C d c 42$, significantly inhibited acidic $\mathrm{pH}_{e}$ induction of MMP-9. Pull-down assays showed that acidic $\mathrm{pH}_{e}$ increased the activated form of RhoA. Forced expression of constitutively active RhoA induced MMP-9 production, even at neutral $\mathrm{pH}_{e}$. RhoA siRNA also reduced acidic $\mathrm{pH}_{e}$ induced PLD activity. Specific inhibition of PLD1 and Pldl gene knockout significantly reduced acidic $\mathrm{pH}_{e}$-induced MMP-9 expression. In contrast, PLD2 inhibition or knockout had no effect on MMP-9 expression. These findings suggested that RhoA-PLD1 signaling is involved in acidic $\mathrm{pH}_{e}$ induction of MMP-9.
\end{abstract}

\section{Introduction}

Tumor cells generate energy through aerobic glycolysis rather than through oxidative phosphorylation in mitochondria. Thus, tumor cells are characterized by acidic extracellular $\mathrm{pH}\left(\mathrm{pH}_{e}\right)$, a phenomenon known as the Warburg effect, due to lactate production through aerobic glycolysis. $\mathrm{H}^{+}$generated during

Correspondence to: Dr Yasumasa Kato, Department of Oral Function and Molecular Biology, Ohu University School of Dentistry, 31-1 Misumido, Tomita-machi, Koriyama 963-8611, Japan

E-mail: yasumasa-kato@umin.ac.jp

*Contributed equally

Key words: matrix metalloproteinase-9, acidic extracellular $\mathrm{pH}_{e}$, RhoA, phospholipase D1, melanoma glycolysis must be secreted to maintain a neutral or weakly alkaline intracellular $\mathrm{pH}$. Several mechanisms are involved in $\mathrm{H}^{+}$secretion, including transporters and/or exchangers such as monocarboxylate transporters (MCTs), which act as $\mathrm{H}^{+}$-lactate co-transporters, and $\mathrm{Na}^{+} / \mathrm{H}^{+}$exchangers (1). Acidity is also caused by $\mathrm{CO}_{2}$ generated through the pentose phosphate pathway (2). We have reported that acidic $\mathrm{pH}_{e}$ induces the expression of matrix metalloproteinase-9 (MMP-9), acting for type IV collagen break down $(3,4)$. The ability of acidic $\mathrm{pH}_{e}$ to induce tumor invasion and metastasis (5-10) suggests that acidic $\mathrm{pH}_{e}$ is an important microenvironment supporting tumor malignancy.

The epithelial mesenchymal transition (EMT) is a critical process for tumor invasion and metastasis. EMT can be mediated by growth factors, including transforming growth factor (TGF)- $\beta$ (11). Notably, we and others have reported that acidic $\mathrm{pH}_{e}$ induces EMT in several cell models $(10,12)$. Although actin cytoskeletal reorganization is involved in EMT, disruption of this pathway was reported associated with the downregulation of MMP-9 expression $(13,14)$. Indeed, the intracellular signaling pathway that involves acidic $\mathrm{pH}_{e}$ has not been completely elucidated (15-25).

Phospholipase D (PLD) is an esterase that hydrolyzes the phospholipids of plasma membranes of mammalian cells. PLD has two major isozymes, PLD1 and PLD2 (26), which localize at perinuclear regions and plasma membranes, respectively (27). Activators of these enzymes include phosphatidylinositol 4,5-bisphosphate (PIP2), small GTPases and ADP-ribosylation factors. Although melanocytes possess negligible levels of PLD1 and PLD2, melanomas express much higher levels of PLD1 (28). In contrast, PLD2 plays a role in the progression of colorectal cancer (29). Thus, the association between these isozymes and malignant phenotypes is likely cell type specific. We have reported that acidic $\mathrm{pH}_{e}$ induces Mmp-9 mRNA expression through intracellular pathways involving $\mathrm{Ca}^{2+}$-triggered PLD, mitogen activated protein (MAP) kinase and nuclear factor- $\mathrm{\kappa B}(\mathrm{NF}-\mathrm{\kappa B})(15,16)$ and acidic sphingomyelinase and NF- $\mathrm{KB}$ (16). However, the mechanism underlying acidic $\mathrm{pH}_{e}$-induced PLD isozyme expression remains unclear. The present study was designed to assess the role of the RhoA-PLD1 axis in acidic $\mathrm{pH}_{e}$-induced MMP-9 production. 


\section{Materials and methods}

Reagents. Dulbecco's modified Eagle's medium (DMEM), Ham's F12 medium, and High Capacity RNA-to-cDNA kits were purchased from Life Technologies (Grand Island, NY, USA). Simvastatin and C3 exoenzyme from Clostridium botulinum were from Merck Millipore (Darmstadt, Germany). Rhodamine-phalloidin and RhoA Pull-down Activation Assay Biochem kits were from Cytoskeleton, Inc. (Denver, CO, USA). Isogen total RNA extraction kits were purchased from Nippon Gene (Tokyo, Japan), and SYBR Premix Ex Taq II and Xfect Transfection reagent were from Takara Bio (Tokyo, Japan). VU0359595 and CAY10594 were from Cayman Chemical (Ann Arbor, MI, USA). Fetal bovine serum (FBS) was from HyClone Laboratories Inc. (South Logan, UT, USA). The blocking reagent N102 was from NOF Corp. (Tokyo, Japan). Immobilon-P PVDF membranes and chemiluminescence reagent were from Merck Millipore (Billerica, MA, USA). Avidin-conjugated horseradish peroxidase (HRP) was from Bio-Rad Laboratories (Hercules, CA, USA). Dual reporter assay kits were from Toyo Ink (Tokyo, Japan).

Vectors and transfection. Constitutively active RhoA vector (pRK5mycL63RhoA) and its control vector (pRK5myc) were the kind gifts of Dr Alan Hall, Memorial Sloan Kettering Cancer Center (New York, NY, USA). The luciferase reporter gene constructs driven by the 5'-flanking region of human MMP-9 (-670) were from Dr Douglas D. Boyd, MD Anderson Cancer Center (Houston, TX, USA). pSpCas9(BB)-2A-GFP (PX458) was obtained from Addgene (Cambridge, MA, USA), and the cytomegalovirus-driven Renilla luciferase reporter vector (pRL-CMV) was from Promega (Madison, WI, USA). Vectors were transfected with Xfect Transfection reagent according to the manufacturer's protocol.

Cell and cell culture. B16-BL6 cells were kindly provided by Dr Kaoru Miyazaki, Yokohama City University (Yokohama, Japan). The basal culture medium consisted of a 1:1 mixture of Dulbecco's modified Eagle's medium and Ham's F-12 medium (DMEM/F12) supplemented with $4 \mathrm{mM}$ phosphoric acid, $15 \mathrm{mM}$ HEPES, $1.8 \mathrm{~g} / 1 \mathrm{NaHCO}_{3}, 100$ units/ml penicillin G, and $0.1 \mathrm{mg} / \mathrm{ml}$ streptomycin sulfate, adjusted to the desired $\mathrm{pH}$ with $\mathrm{HCl}$ or $\mathrm{NaOH}$. For serial culture, basal medium at $\mathrm{pH} 7.4$ was supplemented with $10 \%$ fetal bovine serum (FBS). All cells were cultured at $37^{\circ} \mathrm{C}$ in a $5 \% \mathrm{CO}_{2}$ incubator.

Immunofluorescence microscopy. Cells were incubated in basal medium (pH 7.4) containing 10\% FBS for 1 day on glass coverslips in 6-well plates. The cells were fixed with $4.0 \%$ paraformaldehyde in phosphate-buffered saline (PBS), $\mathrm{pH}$ 7.4, and permeabilized in PBS containing $0.2 \%$ Triton X-100. After washing with PBS, the cells were incubated with $20 \%$ N102 blocking reagent in PBS. For F-actin staining, the cells were incubated with rhodamine-phalloidin $(1 \mathrm{U} / \mathrm{ml})$ for $30 \mathrm{~min}$ at room temperature, followed by three washes with PBS.

Zymography. MMP-9 activity was assessed by zymography, essentially as previously described $(3,4,10,15,16,30)$. Briefly, conditioned media were collected from the cultures and centrifuged to remove cellular debris. The supernatants were mixed with 2.5 volumes of acetone and centrifuged. The precipitated proteins were dissolved in non-reducing sample buffer for sodium dodecyl sulfate polyacrylamide gel electrophoresis (SDS-PAGE). The samples were electrophoresed on $7.5 \%$ polyacrylamide gels containing $0.1 \%$ gelatin. The gels were washed with $2.5 \%$ Triton X-100 containing $50 \mathrm{mM}$ Tris- $\mathrm{HCl}(\mathrm{pH} 7.5)$ and $0.1 \mathrm{M} \mathrm{NaCl}$ at room temperature for $2 \mathrm{~h}$, and incubated in $50 \mathrm{mM}$ Tris-HC1 (pH 7.5) containing $10 \mathrm{mM} \mathrm{CaCl}_{2}$ at $37^{\circ} \mathrm{C}$ for $20 \mathrm{~h}$, and stained with Coomassie brilliant blue R-250.

Pull-down assays. Active RhoA was measured using RhoA Pull-down Activation Assay Biochem kits. Because the GTP-bound form of active RhoA specifically binds rhotekin peptide, consisting of the Rho binding region (amino acids 7-89), fused to glutathione S-transferase (GST-rhotekin), this complex was purified using glutathione affinity beads and active RhoA level analyzed by immunoblotting with anti-RhoA antibody as previously described (15). Briefly, the complexes were separated by $10 \%$ SDS-PAGE and transferred onto Immobilon-P PVDF membranes. The membranes were blocked with TBS-T (20 mM Tris- $\mathrm{HCl}, \mathrm{pH} 7.5,150 \mathrm{mM}$ $\mathrm{NaCl}$, and $0.05 \%$ Tween-20) containing $20 \%$ blocking reagent N102, treated with anti-RhoA antibody, and incubated with biotin-conjugated secondary antibody and avidin-conjugated horseradish peroxidase. Signals were detected with enhanced chemiluminescence reagents. As a positive control, total RhoA level was analyzed in cell lysates.

Mmp-9 promoter assay. MMP-9 promoter activity was measured using luciferase reporter gene assays with an MMP-9 promoter construct, as previously described (15). Transfection efficiency was monitored by co-transfection with Renilla luciferase reporter vector (pRL-CMV), with reporter activity measured using a dual reporter assay kit, according to the manufacturer's protocol.

Gene knockout of PLD isozymes. Cells with knockout of either the PLD1 or PLD2 were generated using the CRISPR-Cas9 system (31). Single guide RNA (sgRNA) sequences targeting PLD1 and PLD2 were 5'-gtggaatatgacgcatctccagg-3' and 5'-ttg aggtccaggtcggaaaaagg-3', respectively. Vectors were transfected with Xfect Transfection reagent. Clones showing lack of target gene expression were selected by the colony formation method.

PLD activity. PLD activity was indirectly measured using PLD assay kits (BioVision, Milpitas, CA, USA), according to the manufacturer's protocol. Because PLD cleaves phosphatidylcholine to choline and phophatide, choline was oxidized with choline oxidase, yielding $\mathrm{H}_{2} \mathrm{O}_{2}$, which was measured using a $\mathrm{H}_{2} \mathrm{O}_{2}$-sensitive probe at $570 \mathrm{~nm}$.

Reverse transcription quantitative polymerase chain reaction $(R T-q P C R)$. Total RNA was purified with Isogen and reversetranscribed to cDNA using a High-Capacity cDNA Reverse Transcription kit. Sequences corresponding to Pld1, Pld2, $M M P-9$ and Actb ( $\beta$-actin) mRNAs were amplified using specific primers and SYBR Premix Ex Taq II in a Thermal Cycler Dice real-time system (TP-870; Takara Bio). The 
A

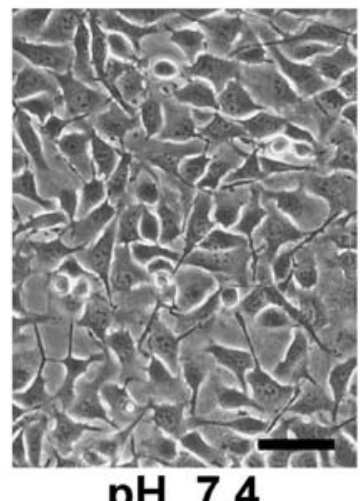

$\mathrm{pH}_{e} 7.4$

B

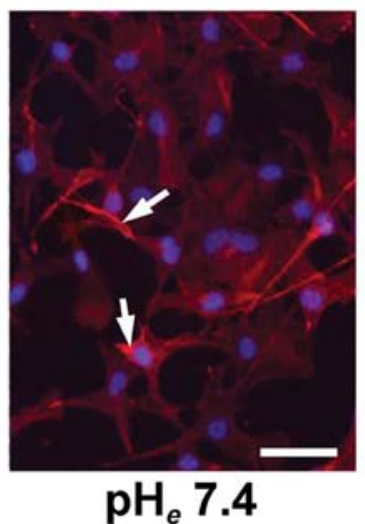

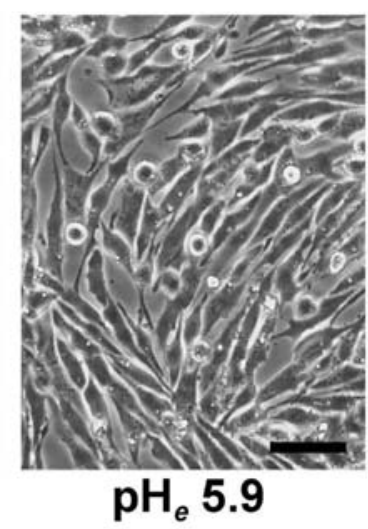

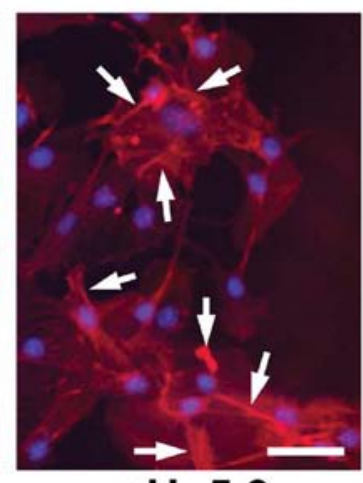

$\mathrm{pH}_{e} 5.9$

Figure 1. Morphological changes in BL6 cells in acidic medium. Serumstarved cells were cultured in physiological $\mathrm{pH}$ and acidic medium at $37^{\circ} \mathrm{C}$. (A) Phase contrast microscopy of cells incubated for $48 \mathrm{~h}$ in acidic medium. (B) Immunofluorescence assay of cells incubated in acidic medium for $24 \mathrm{~h}$, fixed with $4.0 \%$ paraformaldehyde and stained for F-actin with rhodaminephalloidin (red). Most acidic $\mathrm{pH}_{e}$-induced actin stress fibers were associated with the plasma membrane (white arrows). Scale bar, $50 \mu \mathrm{m}$.

specific primer sequences were $5^{\prime}$-acacaccggtgtgcggatct-3' (upstream) and 5'-cgtggtctgggtgtctcatc-3' (downstream) for Pld1 (134 bp); 5'-catcagcatgacagctatgcc-3' (upstream) and 5'-ttcttccgccttcctcttga-3' (downstream) for Pld2 (219 bp); 5'-gc cetggaactcacacgaca-3' (upstream) and 5'-ttggaaactcacacgcca gaa-3' (downstream) for Mmp-9 (85 bp); and 5'-catccgtaaagacc tctatgccaac-3' (upstream) and 5'-atggagccaccgatccaca-3' (downstream) for $\beta$-actin $(85 \mathrm{bp})$. The levels of expression of Pld1, Pld2 and Mmp-9 mRNAs were normalized to those of $\beta$-actin mRNA in the same samples.

Statistical analysis. Statistical significance was determined by the Student's t-test. P-values $<0.05$ were considered to indicate a statistically significant result.

\section{Results}

Reduction of Rho inhibits acidic $\mathrm{pH}_{e^{-}}$-induced MMP-9 production. We have reported that acidic $\mathrm{pH}_{e}$-induced morphological changes in B16-F10 melanoma (3) and Lewis lung carcinoma (10) cell lines, with these cells showing a fibroblastic morphology. Similarly, an acidic $\mathrm{pH}_{e}$-induced morphological changes, independently of cell density, in B16-BL6 cells (Fig. 1A), and enhanced the accumulation of F-actin aggregates, most of which were associated with the
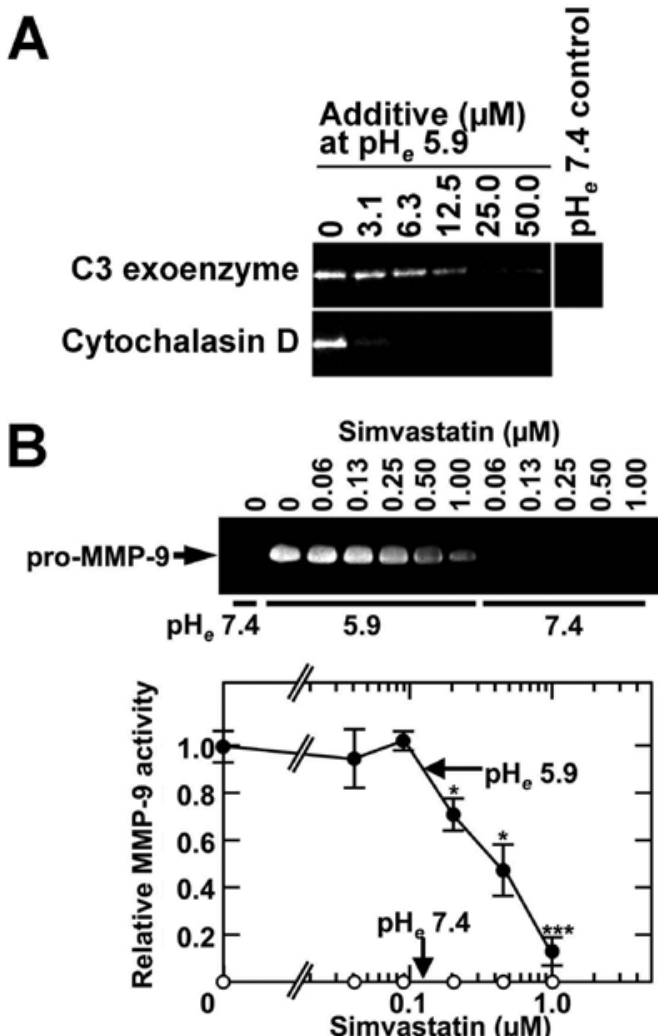

Figure 2. Effects of C3 exoenzyme (A), cytochalasin D (A), and simvastatin (B) on acidic $\mathrm{pH}_{e}$-induced MMP-9 expression. Serum-starved cells were preincubated with $\mathrm{C} 3$ exoenzyme, simvastatin or cytochalasin D at indicated concentration for $1 \mathrm{~h}$ and incubated in acidic medium in the presence of the respective inhibitors for $24 \mathrm{~h}$. MMP-9 activity in the culture medium was analyzed by zymography. Data are expressed as means $\pm \mathrm{SE}(\mathrm{n}=3) .{ }^{*} \mathrm{P}<0.05$; **** $\mathrm{P}<0.001$

plasma membrane (Fig. 1B). Because small G-proteins such as RhoA play important roles in actin reorganization (32), we tested whether cytochalasin D and C3 exoenzyme, which specifically inhibit actin polymerization and Rho, respectively, reduced acidic $\mathrm{pH}_{e}$-induced MMP-9 production, finding that both of these agents inhibited MMP-9 induction (Fig. 2A). Because geranylgeranylation is essential for Rho activation and statins can inactivate $\mathrm{R}$ ho by reducing geranylgeranylation (32), we tested the effects of simvastatin on these cultures, finding that simvastatin inhibited acidic $\mathrm{pH}_{e}$-induced MMP-9 production in a dose-dependent manner (Fig. 2B). To assess the contribution of RhoA to the acidic $\mathrm{pH}_{e}$ signaling pathway responsible for the induction of MMP-9, we treated cells with $R h o A$ siRNA. We found that RhoA siRNA significantly inhibited MMP-9 induction, whereas Racl siRNA and $C d c 42$ siRNA did not (Fig. 3A). Pull-down assays showed that acidic $\mathrm{pH}_{e}$ increased the level of active RhoA (Fig. 3B). Furthermore, transduction of a constitutively active RhoA expression vector into B16-BL6 cells resulted in the induction of MMP-9, even at physiological $\mathrm{pH}_{e}$ (Fig. 3C). Taken together, these findings suggested that RhoA is a molecule that transduces acidic signaling to induce expression of MMP-9.

PLD1 is a downstream effector of acidic $\mathrm{pH}_{e}$ signaling in MMP-9 induction. We previously reported that PLD is important for transducing acidic $\mathrm{pH}_{e}$ signaling $(15,16)$. Moreover, 


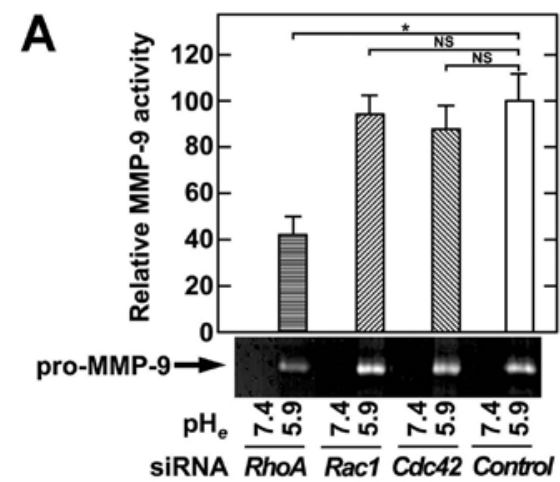

B

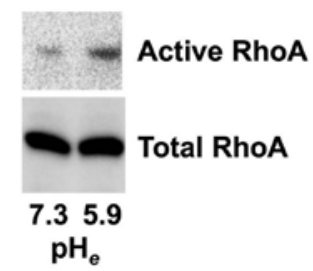

C

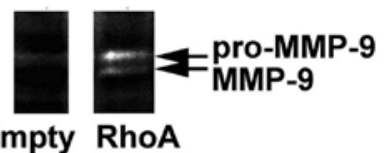

D

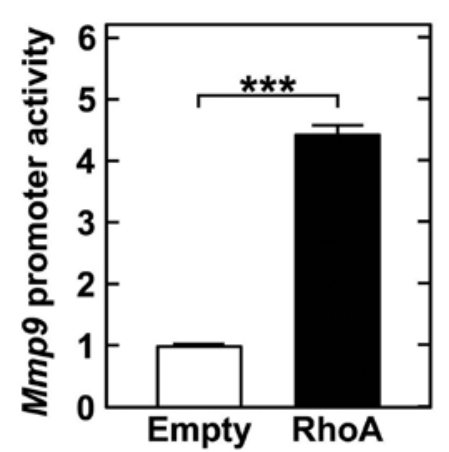

Figure 3. RhoA is a transducer of acidic $\mathrm{pH}_{e}$ signaling that induces MMP-9 production. (A) RhoA siRNA but not Racl or $C d c 42$ siRNA inhibited acidic $\mathrm{pH}_{e}$-induced MMP-9 expression. The siRNAs were transfected into cells under serum-free conditions. After $24 \mathrm{~h}$, the cells were stimulated by acidic medium for another $24 \mathrm{~h}$, and MMP-9 secretion into the culture medium was analyzed by zymography. The intensity of gelatinolytic bands was measured and plotted relative to control at $\mathrm{pH}_{e}$ 5.9. (B) Assessment of acidic $\mathrm{pH}_{e}$ activated RhoA by pull-down assays using GST-Rhotekin. Introduction of a constitutively active RhoA expression vector (pRK5mycL63RhoA) into the cells induced MMP-9 activity that was detected by zymography. The control consisted of the empty vector pRK5myc (C), with promoter activity determined by dual promoter assays (D). Data were expressed as mean $\pm \mathrm{SE}(\mathrm{n}=3)$. ${ }^{*} \mathrm{P}<0.05 ;{ }^{* * * *} \mathrm{P}<0.001 ; \mathrm{NS}$, not significant.

RhoA has been found to activate PLD (26). Therefore, we tested the effects of RhoA siRNA on PLD activity. RhoA siRNA reduced not only PLD activity at $\mathrm{pH}_{e} 5.9$ but also the basal PLD activity at $\mathrm{pH}_{e} 7.4$ (Fig. 4). Because PLD has two isozymes, PLD1 and PLD2 (26), we determined which one is involved in the acidic $\mathrm{pH}_{e}$ induction of MMP-9. We found that the specific PLD1 inhibitor VU0359595 significantly reduced acidic $\mathrm{pH}_{e}$-induced MMP-9 production, whereas the specific PLD2 inhibitor CAY10594 did not (Fig. 5A and B). This was confirmed by RT-qPCR assessments of the level of

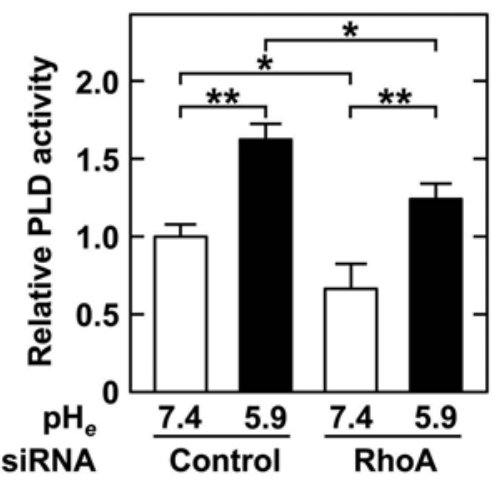

Figure 4. RhoA siRNA reduces PLD activity. Cells transfected with RhoA siRNA were cultured in neutral and acidic medium for $24 \mathrm{~h}$. The cells were lysed and PLD activity in the supernatants determined. Data were expressed as mean $\pm \mathrm{SE}(\mathrm{n}=3) .{ }^{*} \mathrm{P}<0.05 ;{ }^{* *} \mathrm{P}<0.01$.
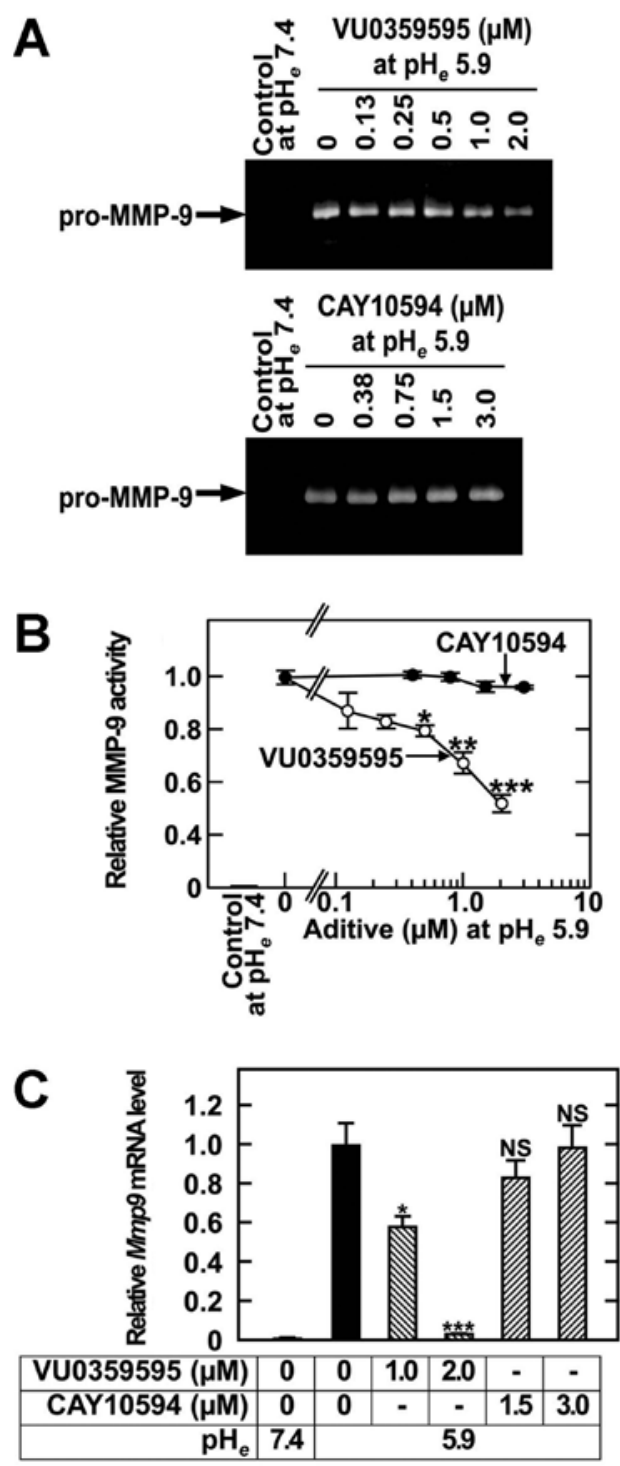

Figure 5. Attenuation of acidic $\mathrm{pH}_{e}$-induced MMP-9 production by a specific inhibitor of PLD1, but not of PLD2. Serum-starved cells were pretreated with either the PLD1 inhibitor VU0359595 or the PLD2 inhibitor CAY10594 at neutral $\mathrm{pH}$ for $1 \mathrm{~h}$ then stimulated by acidic medium containing the respective inhibitor for $24 \mathrm{~h}$. (A) Zymography; (B) intensity of the gelatinolytic bands in panel A. Control values $\left(\mathrm{pH}_{e} 7.4\right)$ are hidden by the basal line due to the small value; (C) RT-qPCR. Data are expressed as mean $\pm \mathrm{SE}$. ${ }^{*} \mathrm{P}<0.05$; ${ }^{* *} \mathrm{P}<0.01 ;{ }^{* * *} \mathrm{P}<0.001 ; \mathrm{NS}$, not significant. 

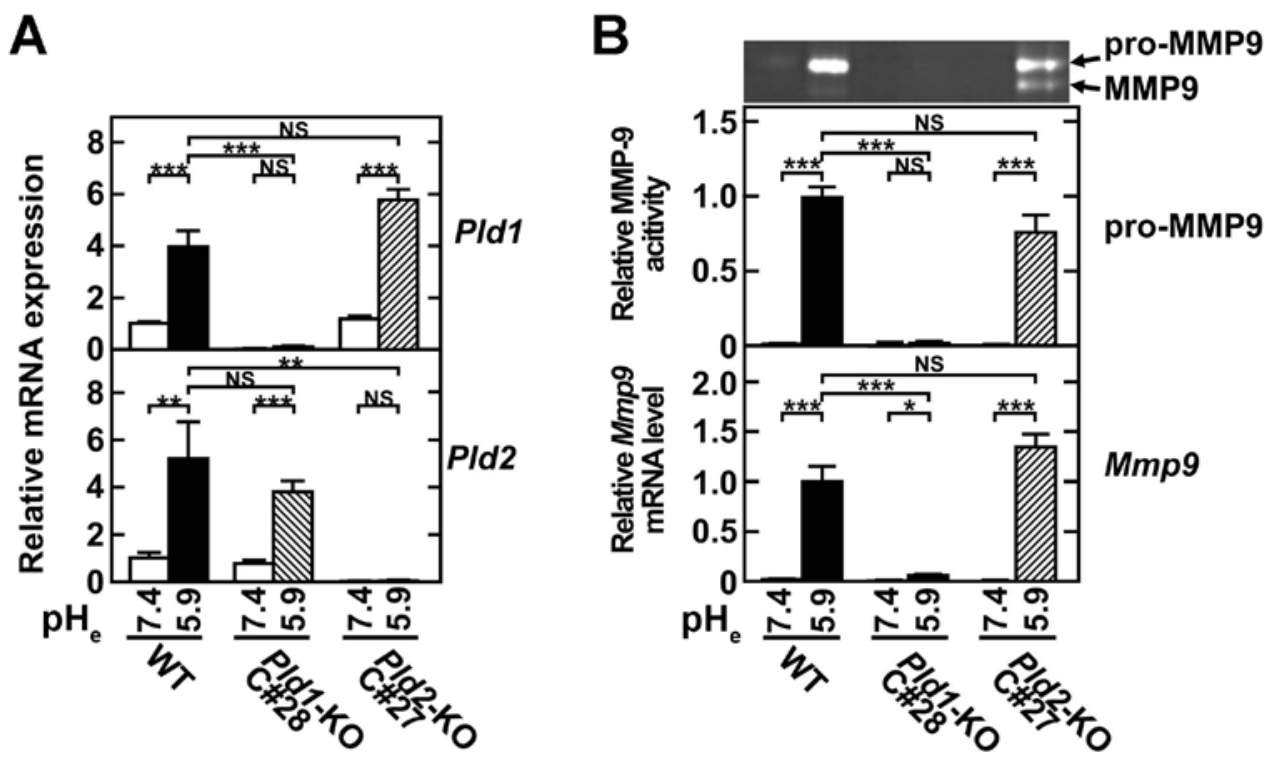

Figure 6. Pld1 gene knock-out cells do not respond to acidic $\mathrm{pH}_{e}$. The CRISPR/Cas9 system was used to knock out the Pld1 or Pld2 gene. Cell clones were isolated by colony formation. (A) Confirmation of Pld1 and Pld2 mRNA levels in each clone by RT-qPCR. Pld1 knockout clone \#28 (Pld1-KO C\#28); Pld2 knockout clone \#28 (Pld2-KO C\#27). These clones and their parental BL6 cells with wild-type (WT) Pld genes were serum-starved and treated with acidic medium. (B) Zymography (upper panel), intensity of gelatinolytic activity of zymograms (middle panel), and RT-qPCR for $M m p-9$ (bottom panel). Data are expressed as mean $\pm \mathrm{SE}$. ${ }^{*} \mathrm{P}<0.05 ;{ }^{* *} \mathrm{P}<0.01 ;{ }^{* * *} \mathrm{P}<0.001 ; \mathrm{NS}$, not significant.

Mmp-9 mRNA expression (Fig. 5C). Furthermore, we used the CRISPR-Cas9 system to knockout either PLD isozyme (Fig. 6A), finding that PLD1 KO completely inhibited acidic $\mathrm{pH}_{e}$-induced MMP-9 production whereas PLD2 KO had no effect on its expression (Fig. 6B). This result was also confirmed by RT-qPCR for Mmp-9 mRNA (Fig. 6B). Acidic $\mathrm{pH}_{e}$ also enhanced the levels of both PLD1 and PLD2 mRNAs (Fig. 6C). Taken together, these findings suggest that RhoA-PLD1 plays an important role in acidic $\mathrm{pH}_{e}$ induction of MMP-9.

\section{Discussion}

The present study expands on our previous findings, showing that acidic $\mathrm{pH}_{e}$ activates PLD leading to MMP-9 induction. The present study initially focused on the mechanism of PLD activation. PLD activity has been closely associated with actin reorganization, as small GTPases such as the Rho family and Arf synergistically activate PLD (26). RhoA is a more potent PLD activator than other members of the Rho family such as Rac1 and Cdc42, with the latter two shown to rescue PLD activity when RhoA was inactivated (33). This study showed that RhoA knockdown by a specific siRNA reduced acidic $\mathrm{pH}_{e}$-induced MMP-9 expression, whereas Rac1 and $\mathrm{Cdc} 42$ siRNAs had no effect. These findings indicate that Racl and $\mathrm{Cdc} 42$ are not involved in acidic $\mathrm{pH}_{e}$ signaling and that they cannot rescue RhoA activity in the PLD-MMP-9 axis. These findings are in good agreement with results showing the importance of RhoA activation in MMP-9 expression $(34,35)$. Our and other research groups have investigated the role of acidic $\mathrm{pH}_{e}$ in the induction of EMT $(10,12)$, showing that RhoA activation is important for actin reorganization in EMT. Cytochalasin D was found to enhance mesenchymal epithelial transition along with E-cadherin by reducing RhoA activity and reduced expression of vimentin and N-cadherin (13). Sustained Ras activity was shown to reduce Rac, which can inhibit Rho function, whereas induction of Rho can result in EMT in transformed cells. Cytoskeletal rearrangement induced by acidic $\mathrm{pH}_{e}$ is therefore important for EMT through the RhoA-PLD axis.

TPA is an analog of diacylglycerol that activates protein kinase $\mathrm{C}$ (PKC) isoforms such as conventional PKC (DAG ${ }^{-}$and $\mathrm{Ca}^{2+}$-dependent; $\alpha, \beta \mathrm{I}, \beta \mathrm{II}$ and $\gamma$ ) and novel PKC (DAG-dependent, but $\mathrm{Ca}^{2+}$-independent; $\delta, \varepsilon, \eta$ and $\theta$ ), contributing to the activation of AP-1 and PLD (36). We have shown that TPA did not induce MMP-9 expression in B16-BL6 cells at neutral $\mathrm{pH}_{e}$ but enhanced MMP-9 expression at acidic $\mathrm{pH}_{e}$, at least in part through $\mathrm{NF}-\kappa \mathrm{B}$, but not AP-1 activation $(15,16)$. However, bisindolylmaleimide III, a potent PKCa inhibitor, attenuated MMP-9 expression at low $\mathrm{pH}_{e}$ (data not shown).

PLD has two major isozymes, PLD1 and PLD2 (26). To determine which of these isozymes contributed to acidic $\mathrm{pH}_{e}$ signaling, we used isozyme specific inhibitors and gene knockout technique for each PLD. These experiments showed that PLD1 was responsible for the induction of Mmp-9 mRNA expression at acidic $\mathrm{pH}_{e}$. Human melanoma cells predominantly express PLD1 (28). Although PLD1 activity is inducible, PLD2 activity is constitutive and shows a reduced response to stimulation by small GTPases (27). TPA was found to enhance $P l d 1$, but not Pld2, promoter activity, resulting in MMP-9 secretion through PKC $\beta$ II-Ras-MAP kinase-NF- $\kappa \mathrm{B}$ signaling (37). Our results also showed that PLD1, but not PLD2, was associated with acidic $\mathrm{pH}_{e}$ induced MMP-9 production. We also found that increased PLD activity may be due to increases in both $P l d l$ gene expression and RhoA-induced PLD1 activation, as well as to $\mathrm{Ca}^{2+}$ influx (16), suggesting the existence of an intracellular signaling loop for gain of function of PLD1. Acidic $\mathrm{pH}_{e}$ increased the expression of Pld2 mRNA in PLD1-KO cells, but these cells did not respond to acidic medium. This finding suggests that PLD2 cannot compensate for PLD1 in the acidic $\mathrm{pH}_{e}$ signaling. 
We have reported that PLD activation leads to MMP-9 expression through $\mathrm{NF}_{-} \kappa \mathrm{B}$ (15). Deletion of the NF- $\mathrm{B}$ binding-site from the $\mathrm{Mmp}-9$ promoter construct attenuated acidic $\mathrm{pH}_{e}$-induced $\mathrm{Mmp}-9$ promoter activity when compared with wild-type (WT) promoter (15). In contrast, the promoter activity ratio between neutral and acidic $\mathrm{pH}_{e}$ was similar in the mutant and WT constructs, suggesting that PLD-NF- $\kappa \mathrm{B}$ signaling is essential for $M m p-9$ expression. In agreement, this study showed that RhoA siRNA reduced PLD activities but had no effect on the activity ratio of neutral and acidic $\mathrm{pH}_{e}$. Taken together, these findings indicate that PLD1 activity is essential in the induction of Mmp-9 mRNA, with additional signaling, such as acidic sphingomyelinase, required for further induction of Mmp-9 gene expression by acidic $\mathrm{pH}_{e}(16)$.

Generally, tumor cells become hypoxic $\sim 100 \mu \mathrm{m}$ from blood vessels. Because the expression of metabolic enzymes in glycolysis, such as glyceraldehyde dehydrogenase (GAPDH) and enolase, is dependent on hypoxia-inducible factor (HIF) (38), increased tumor acidity may occur in hypoxic areas, although hypoxia may not be essential for tumor acidity (2). Increases in glucose products, such as pyruvate and lactate, can result in the accumulation of HIF-induced proteins under aerobic conditions (39), indicating that glycolysis can associate the signaling of both hypoxia and acidic $\mathrm{pH}_{e}$. Hypoxia has been shown to induce the EMT in gastric cancer cells through TGF $\beta$ signaling in an autocrine manner (40). TGF acts synergistically with other growth factors, including epidermal growth factor (EGF) and basic fibroblast growth factor (bFGF) $(41,42)$. Further analysis is required to determine relationships between growth factors and acidic $\mathrm{pH}_{e}$ signaling

In conclusion, the present study investigated whether acidic $\mathrm{pH}_{e}$, a hallmark of malignant tumors, contributes to the metastatic phenotype through the RhoA-PLD1 axis. Inhibition of isoprenylation by statins such as simvastatin is useful for preventing metastasis driven by acidic $\mathrm{pH}_{e}$.

\section{Acknowledgements}

We thank Dr Alan Hall (Memorial Sloan Kettering Cancer Center, deceased 3rd May, 2015), Dr Douglas D. Boyd (MD Anderson Cancer Center, University of Texas, TX, USA) and Kaoru Miyazaki (Kanagawa Cancer Center Research Institute, Japan) for providing constitutive RhoA expression vector, the luciferase reporter gene constructs driven by the 5'-flanking region of human MMP-9 (-670), and B16-BL6 cells, respectively. We also thank Dr Ryu-Ichiro Hata (Kanagawa Dental University, Japan) for his critical suggestions. The present study was partly supported by Youth Encouragement Grants (to S.Y.) from Ohu University, Japan.

\section{References}

1. Kato Y, Ozawa S, Miyamoto C, Maehata Y, Suzuki A, Maeda T and Baba Y: Acidic extracellular microenvironment and cancer. Cancer Cell Int 13: 89, 2013.

2. Helmlinger G, Sckell A, Dellian M, Forbes NS and Jain RK: Acid production in glycolysis-impaired tumors provides new insights into tumor metabolism. Clin Cancer Res 8: 1284-1291, 2002 .

3. Kato Y, Nakayama Y, Umeda M and Miyazaki K: Induction of 103-kDa gelatinase/type IV collagenase by acidic culture conditions in mouse metastatic melanoma cell lines. J Biol Chem 267: 11424-11430, 1992.
4. Kato Y, Ozono S, Shuin T and Miyazaki K: Slow induction of gelatinase B mRNA by acidic culture conditions in mouse metastatic melanoma cells. Cell Biol Int 20: 375-377, 1996.

5. Martínez-Zaguilán R, Seftor EA, Seftor RE, Chu YW, Gillies RJ and Hendrix MJ: Acidic pH enhances the invasive behavior of human melanoma cells. Clin Exp Metastasis 14: 176-186, 1996.

6. Lora-Michiels M, Yu D, Sanders L, Poulson JM, Azuma C, Case B, Vujaskovic Z, Thrall DE, Charles HC and Dewhirst MW: Extracellular $\mathrm{pH}$ and $\mathrm{P}-31$ magnetic resonance spectroscopic variables are related to outcome in canine soft tissue sarcomas treated with thermoradiotherapy. Clin Cancer Res 12: 5733-5740, 2006.

7. Gatenby RA, Gawlinski ET, Gmitro AF, Kaylor B and Gillies RJ: Acid-mediated tumor invasion: A multidisciplinary study. Cancer Res 66: 5216-5223, 2006.

8. Moellering RE, Black KC, Krishnamurty C, Baggett BK, Stafford P, Rain M, Gatenby RA and Gillies RJ: Acid treatment of melanoma cells selects for invasive phenotypes. Clin Exp Metastasis 25: 411-425, 2008.

9. Robey IF, Baggett BK, Kirkpatrick ND, Roe DJ, Dosescu J, Sloane BF, Hashim AI, Morse DL, Raghunand N, Gatenby RA, et al: Bicarbonate increases tumor $\mathrm{pH}$ and inhibits spontaneous metastases. Cancer Res 69: 2260-2268, 2009.

10. Suzuki A, Maeda T, Baba Y, Shimamura K and Kato Y: Acidic extracellular $\mathrm{pH}$ promotes epithelial mesenchymal transition in Lewis lung carcinoma model. Cancer Cell Int 14: 129, 2014.

11. Curry JM, Sprandio J, Cognetti D, Luginbuhl A, Bar-ad V, Pribitkin E and Tuluc M: Tumor microenvironment in head and neck squamous cell carcinoma. Semin Oncol 41: 217-234, 2014.

12. Peppicelli S, Bianchini F, Torre E and Calorini L: Contribution of acidic melanoma cells undergoing epithelial-to-mesenchymal transition to aggressiveness of non-acidic melanoma cells. Clin Exp Metastasis 31: 423-433, 2014.

13. Shankar J and Nabi IR: Actin cytoskeleton regulation of epithelial mesenchymal transition in metastatic cancer cells. PLoS One 10: e0119954, 2015.

14. Dobrowolski JM and Sibley LD: Toxoplasma invasion of mammalian cells is powered by the actin cytoskeleton of the parasite. Cell 84: 933-939, 1996.

15. Kato Y, Lambert CA, Colige AC, Mineur P, Noël A, Frankenne F, Foidart JM, Baba M, Hata R, Miyazaki K, et al: Acidic extracellular $\mathrm{pH}$ induces matrix metalloproteinase-9 expression in mouse metastatic melanoma cells through the phospholipase D-mitogen-activated protein kinase signaling. J Biol Chem 280: 10938-10944, 2005.

16. Kato Y, Ozawa S, Tsukuda M, Kubota E, Miyazaki K, St-Pierre Y and Hata R: Acidic extracellular $\mathrm{pH}$ increases calcium influx-triggered phospholipase $\mathrm{D}$ activity along with acidic sphingomyelinase activation to induce matrix metalloproteinase-9 expression in mouse metastatic melanoma. FEBS J 274: 3171-3183, 2007.

17. Xu L, Fukumura D and Jain RK: Acidic extracellular $\mathrm{pH}$ induces vascular endothelial growth factor (VEGF) in human glioblastoma cells via ERK1/2 MAPK signaling pathway: Mechanism of low pH-induced VEGF. J Biol Chem 277: 11368-11374, 2002.

18. Chen Y, Kung HN, Chen CH, Huang SH, Chen KH and Wang SM: Acidic extracellular $\mathrm{pH}$ induces p120-catenin-mediated disruption of adherens junctions via the Src kinase-PKC $\delta$ pathway. FEBS Lett 585: 705-710, 2011.

19. Sarosi GA Jr, Jaiswal K, Herndon E, Lopez-Guzman C, Spechler SJ and Souza RF: Acid increases MAPK-mediated proliferation in Barrett's esophageal adenocarcinoma cells via intracellular acidification through a $\mathrm{Cl}^{-} / \mathrm{HCO}_{3}{ }^{-}$exchanger. Am J Physiol Gastrointest Liver Physiol 289: G991-G997, 2005.

20. Lee YJ, Lee DM and Lee SH: Production of Cyr61 protein is modulated by extracellular acidification and PI3K/Akt signaling in prostate carcinoma PC-3 cells. Food Chem Toxicol 58: 169-176, 2013.

21. Riemann A, Schneider B, Ihling A, Nowak M, Sauvant C, Thews $\mathrm{O}$ and Gekle M: Acidic environment leads to ROS-induced MAPK signaling in cancer cells. PLoS One 6: e22445, 2011.

22. Mochimaru Y, Azuma M, Oshima N, Ichijo Y, Satou K, Matsuda K, Asaoka Y, Nishina H, Nakakura T, Mogi C, et al: Extracellular acidification activates ovarian cancer G-proteincoupled receptor 1 and GPR4 homologs of zebra fish. Biochem Biophys Res Commun 457: 493-499, 2015. 
23. Kotake M, Sato K, Mogi C, Tobo M, Aoki H, Ishizuka T, Sunaga N, Imai H, Kaira K, Hisada T, et al: Acidic $\mathrm{pH}$ increases cGMP accumulation through the OGR1/phospholipase $\mathrm{C} / \mathrm{Ca}^{2+} /$ neuronal NOS pathway in N1E-115 neuronal cells. Cell Signal 26: 2326-2332, 2014.

24. Murata N, Mogi C, Tobo M, Nakakura T, Sato K, Tomura H and Okajima F: Inhibition of superoxide anion production by extracellular acidification in neutrophils. Cell Immunol 259: 21-26, 2009.

25. Mogi C, Tobo M, Tomura H, Murata N, He XD, Sato K, Kimura T, Ishizuka T, Sasaki T, Sato T, et al: Involvement of proton-sensing TDAG8 in extracellular acidification-induced inhibition of proinflammatory cytokine production in peritoneal macrophages. J Immunol 182: 3243-3251, 2009.

26. Bruntz RC, Lindsley CW and Brown HA: Phospholipase D signaling pathways and phosphatidic acid as therapeutic targets in cancer. Pharmacol Rev 66: 1033-1079, 2014.

27. Colley WC, Sung TC, Roll R, Jenco J, Hammond SM, Altshuller Y, Bar-Sagi D, Morris AJ and Frohman MA: Phospholipase D2, a distinct phospholipase D isoform with novel regulatory properties that provokes cytoskeletal reorganization. Curr Biol 7: 191-201, 1997.

28. Riebeling C, Müller C and Geilen CC: Expression and regulation of phospholipase D isoenzymes in human melanoma cells and primary melanocytes. Melanoma Res 13: 555-562, 2003.

29. Saito M, Iwadate M, Higashimoto M, Ono K, Takebayashi $Y$ and Takenoshita S: Expression of phospholipase D2 in human colorectal carcinoma. Oncol Rep 18: 1329-1334, 2007.

30. Maeda T, Suzuki A, Yuzawa S, Baba Y, Kimura Y and Kato Y: Mineral trioxide aggregate induces osteoblastogenesis via Atf6. Bone Rep 2: 36-43, 2015.

31. Ran FA, Hsu PD, Wright J, Agarwala V, Scott DA and Zhang F: Genome engineering using the CRISPR-Cas9 system. Nat Protoc 8: 2281-2308, 2013.

32. Xiao Y, Liang L, Pan Y, Lian F, Li L, Lin H, Fu D, Fan J, Yang X, Sun L, et al: Inhibitory effects of simvastatin on migration and invasion of rheumatoid fibroblast-like synoviocytes by preventing geranylgeranylation of RhoA. Rheumatol Int 33: 389-399, 2013
33. Kuribara H, Tago K, Yokozeki T, Sasaki T, Takai Y, Morii N, Narumiya S, Katada T and Kanaho Y: Synergistic activation of rat brain phospholipase D by ADP-ribosylation factor and rhoA p21, and its inhibition by Clostridium botulinum C3 exoenzyme. J Biol Chem 270: 25667-25671, 1995.

34. Abécassis I, Olofsson B, Schmid M,Zalcman G and Karniguian A RhoA induces MMP-9 expression at CD44 lamellipodial focal complexes and promotes HMEC-1 cell invasion. Exp Cell Res 291: 363-376, 2003.

35. Chandrasekar N, Jasti S, Alfred-Yung WK, Ali-Osman F, Dinh DH, Olivero WC, Gujrati M, Kyritsis AP, Nicolson GL, Rao JS, et al: Modulation of endothelial cell morphogenesis in vitro by MMP-9 during glial-endothelial cell interactions. Clin Exp Metastasis 18: 337-342, 2000.

36. Bosco R, Melloni E, Celeghini C, Rimondi E, Vaccarezza M and Zauli G: Fine tuning of protein kinase $\mathrm{C}$ (PKC) isoforms in cancer: Shortening the distance from the laboratory to the bedside. Mini Rev Med Chem 11: 185-199, 2011.

37. Kang DW, Park MH, Lee YJ, Kim HS, Kwon TK, Park WS and Min S: Phorbol ester up-regulates phospholipase D1 but not phospholipase D2 expression through a PKC/Ras/ERK/ NFkappaB-dependent pathway and enhances matrix metalloproteinase-9 secretion in colon cancer cells. J Biol Chem 283: 4094-4104, 2008.

38. Semenza GL: Regulation of metabolism by hypoxia-inducible factor 1. Cold Spring Harb Symp Quant Biol 76: 347-353, 2011.

39. Lu H, Forbes RA and Verma A: Hypoxia-inducible factor 1 activation by aerobic glycolysis implicates the Warburg effect in carcinogenesis. J Biol Chem 277: 23111-23115, 2002

40. Matsuoka J, Yashiro M, Doi Y, Fuyuhiro Y, Kato Y, Shinto O, Noda S, Kashiwagi S, Aomatsu N, Hirakawa T, et al: Hypoxia stimulates the EMT of gastric cancer cells through autocrine TGF $\beta$ signaling. PLoS One 8: e62310, 2013.

41. Uttamsingh S, Bao X, Nguyen KT, Bhanot M, Gong J, Chan JL, Liu F, Chu TT and Wang LH: Synergistic effect between EGF and TGF-betal in inducing oncogenic properties of intestinal epithelial cells. Oncogene 27: 2626-2634, 2008

42. Shirakihara T, Kawasaki T, Fukagawa A, Semba K, Sakai R, Miyazono K, Miyazawa K and Saitoh M: Identification of integrin $\alpha 3$ as a molecular marker of cells undergoing epithelialmesenchymal transition and of cancer cells with aggressive phenotypes. Cancer Sci 104: 1189-1197, 2013. 